\title{
A summarized review about natural polymers role in floating drug delivery system and in-vivo evaluation studies
}

\author{
Muhammad Umar Javaid ${ }^{1},{ }^{*}$ Qurat-ul-Ain ${ }^{1,2}$, Umer Tahir ${ }^{1,2}$ and Safwan Shahid ${ }^{1}$ \\ ${ }^{1}$ Faculty of Pharmacy, The University of Lahore, Lahore, Pakistan \\ ${ }^{2}$ Foundation for Young Researchers, Lahore, Pakistan
}

\begin{abstract}
The approach of eco-friendly and safe environmental materials for various industrial applications like medicine, agriculture and similar areas is growing rapidly. The advantages of biologically degradable and non-toxic materials like the natural polymers are evident by the mounting level of its use in pharmaceutical field particularly. The various natural polymers have been aiding the drug delivery systems for long time as the drug transporters with the objective of improving the efficacy and efficiency. The floating drug delivery systems are required to possess proper floating capability in gastric systems and use of natural polymers in such delivery systems has been very beneficial. The physical characteristics of natural polymers facilitate them to be brilliant drug carriers for such type of drug delivery systems. The aim of this review is to provide the overview of role of natural polymers in floating drug delivery system, its characteristic effects, ongoing research and trend of future developments and applications in the field.
\end{abstract}

Key Words: Natural Polymers, Advantages, Efficiency, Floating Drug Delivery system, Applications, Transporters.

\section{INTRODUCTION}

In the development of novel drug delivery system, natural polymers and their semi synthetic derivatives broaden admiration. Advantages of natural polymers are their compatibility with other agents and degradability, readily availability and ability for chemical modification. Natural excipients are given preference because synthetic excipients cause unwanted effects in human. Herbal products are safer so now patients looking for the natural herbal constituents. Natural polymers release reformed form of drugs. Studies showed that natural polymers containing formulations release activities of drug influenced by the physiochemical properties, morphology, and release pattern of polymer, shape of dosage form and particle size. (Kumar et al., 2012a). In drug delivery system natural gums have diverse applications as binders, suspending agents, disintegrant and emulsifying agents. They are also useful in preparation of sustained release and immediate release formulations (Goswami and Naik, 2014). Floating system are of two types, effervescent and non-effervescent system, without effecting on gastric emptying rate it remains buoyant or bouncy in stomach for longer time because this system consists of bulk density that is less than gastric fluids. At the time when system floats in gastric substances the drug is released deliberately in certain amount from this system. The best events of these systems are well regulated fluctuations in plasma drug concentration and augmented gastric retention time (Bangalore et al., 2012; Bhowmik et al., 2009).

\section{Advantages of Gastro Retentive Drug Delivery System} GRDDS is suitable for all those drugs which absorbed through stomach and show local action in it, i.e., antacids etc. Due to vigorous intestinal movement poor drug absorption may occur in diarrhea, it can be prevented by

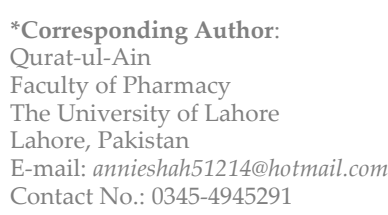

using this system to retain drug and its better response. It increases the patient compliance and lowers the dosing frequency. Therapeutic effect can be improved of drugs having short half-life. In this system the continuous drug release sustains a desired plasma drug concentration. Formulations which are unstable in intestinal $\mathrm{pH}$ can also be used. Dose dumping cannot occur. Sustained and uniform release of drug can prevent the gastric irritation. By the administration of prolonged release gastro retentive dosage forms dissolution in gastric fluid can be maintained as well as in alkaline $\mathrm{pH}$ of small intestine (Kanavaje et al., 2014; Reddy et al., 2013).

Disadvantages of Gastro Retentive Drug Delivery System This system is not suitable for those drug which are acid insoluble or unstable in acidic medium, e.g., phenytoin and erythromycin respectively. It can't be used for those drugs which produces gastric lesions on slow release, e.g., nonsteroidal anti-inflammatory drugs. This system is not compatible with those drugs which absorb specifically in colon, e.g., corticosteroids. Drug delivery systems with increased size may contain the high risk of preservation in stomach for long time and may pose a life threatening effect on further use of this system. For bio adhesive system the most difficult for is the high turnover proportion of gastric mucus. For efficient result and effect, this floating system needs high fluid level in stomach so it can float (Nayak, 2012; Kajale and Chandewar, 2013).

\section{Applications of Gastro Retentive Drug Delivery}

GFDDS stays in stomach for extensive period of time to enhance GRT while sustained drug delivery system shows limited effect due to short retention time in stomach. It can't pass through pylorus because of increased size and low density than their gastric fluids. (Mishra and Gupta, 2012) Those drugs which metabolized in upper GIT, their bioavailability and absorption can be enhanced by using this system. (Makwana et al., 2012) Those drugs that absorbed from the stomach and proximal part of intestine have advantage of this system. It provides sufficient therapeutic level and effect and decreases the systemic exposure 
to the drug and reduced side effects due to slow delivery of drug from this system. It can also reduce the dosing frequency of certain drugs due to prolonged gastric availability, e.g., Feurosemide. (Goyal et al., 2011). This system can decrease the counter action of the body may lead to higher efficiency and productivity of drug. (Kajale and Chandewar, 2013) Unwanted actions or activities of drug in colon can be avoided due to retention of drug in GRDF. Beta lactam antibiotics that absorbed from the small intestine and their presence in the colon may cause microorganism's resistance (Kumar et al., 2012a).

\section{Advantages of Natural Polymers}

Biodegradable or natural polymers can be produced by living organism and are naturally available. They show no adverse reaction on human or on environmental health. Most of the natural polymers are nontoxic and biocompatible because these plant materials are carbohydrates in nature. Natural sources are easily collected in different seasons in large quantities and have low cost. Now in developing countries their productions have been promoted because of its wide use in industries (Tekade and Chaudhari, 2013).

\section{Disadvantages of Herbal Polymers}

They are disclosed to external environment so they may contain microbial contamination. Production of natural polymers depends on environment and various physical factors while synthetic manufacturing is controlled method with fixed amounts of ingredients. The percentage of content and constituents in natural materials may vary due to differences in their collection from different region, and at different times. They may have slow rate of production (Kulkarni et al., 2012).

\section{NATURAL POLYMERS USED IN FLOATING DRUG DELIVERY}

\section{Guar Gum}

Guar gum belongs to family Leguminosae and derived from cyamopsis tetragonolobus kernels. It is also known as Guaran, cluster bean, Cyamopsis, Calcutta lucern and Guarina (Chatrchyan et al., 2014). It is a whitish yellow powder and has taste or odor. It is water soluble and are not soluble in organic solvents (Sahoo et al., 2013). It has increased viscosity and used in solid dosage forms as a disintegrant and binder in pharmaceutical industries (Gomber and Parihar, 2013).

\section{Xanthan Gum}

Bacterium Xanthomonas campestris produced xanthum gum naturally. (Gomber and Parihar, 2013) This gum appears as odorless, free flowing fine powder or cream. Polysaccharide B-1459, Keltrol, Rhodigel, Merezan and Corn sugar gum are soluble in warm or cold water and are insoluble in ethanol and ether. This gum is stable material and is polysaccharide in nature with D-glucose backbone like cellulose. Their aqueous solutions are durable in existance of enzymes, bases, salts, acids and stable at $\mathrm{pH}$ range 3-12 and temperature between $10-60^{\circ} \mathrm{C}$. It is nontoxic and nonirritant and used in cosmetics and food products, in topical and oral pharmaceutical formulations and preparations. It is also used as stabilizing agent, gelling agent, viscosity-increasing agent, suspending agent, emulsifying agent and thickening agent (Kola and Kumar, 2013; Sai Rekha et al., 2015).

\section{Chitosan}

It is composed of glucosamine and Nacetylglucosamine and is linear cationic polysaccharide. Chitosan is prepared by the deacetylation of chitin that is obtained from crustacean shells. (Singh et al., 2011). It is biodegradable, biocompatible and nontoxic (Shah et al., 2013). It is odorless creamy or white flakes or powder and partially insoluble in $95 \%$ ethanol and soluble in water. It is used as viscosity enhancer, mucoadhesive, fil forming agent, tablet binder, coating agent and disintegrant (Sai Rekha et al., 2015).

\section{Pectin}

Pectin is nontoxic and economic polysaccharide extracted from apple pomaces and citrus peels. On the base of both extraction process and source pectin is a complex structure. Actually it's a-D-galacturonic acid polymer with 1-4 linkages. It is used as bulking agent, food additive and a gelling agent (Thirawong et al., 2007) due to the pectin ability to form gel based on degree of esterification and molecular size, it's an alluring candidate for pharmaceutical care, e.g. as drug carrier for controlled released applications (Raj, 2012).

\section{Carrageenan}

Carrageenans, naturally occurring repeating units of galactose and 3, 6 anhydrogalactose high molecular weight anionic gel-forming polysaccharides extracted from red seaweeds species as Euchema, Chondrus crispus, Iridaea. And Gigartina stellate. Depending on degree of sulfation, are classified into different types: $\lambda$-carrageenan (three-sulfate), $\kappa$-(di-sulfate) and $\mathrm{t}-($ mono-sulfate). Highly sulphated $\lambda$ carrageenan is a thickener agent and does not form gel while $\kappa$ - and $\mathrm{t}$-carrageenan forms gel, which influence their release kinetics. (Singh et al., 2011) Carrageenans are mostly utilized because of their superb physical functional properties in food industries, such as bulking agent, thickening, stabilizing abilities and gelling. Because of the high robustness, good compatibility and persistent viscoelasticity of the tablet during granulation and compression, it proved to be useful as tablet excipient agents. Hence for sustainedrelease formulations carrageenans are suitable excipients (Campo et al., 2009).

\section{Gum Karaya}

Gum Karaya is known as Sterculia gum obtained from Sterculiaurens Roxburgh and other species of Sterculia (Family - Sterculiaceae). After acid hydrolysis, Gum Karaya commonly produces D-galactose, D-galacturonic acid, Lrhamnose and small proportions of D-glucuronic acid. Sparingly soluble in water; poorly soluble in $0.1 \mathrm{~N} \mathrm{HCl}$ and simulated gastric fluid; slightly insoluble in ethanol (95\%), other similar organic solvents, and alkali solutions at $\mathrm{pH}$ above approximately 6.5 (Sarathchandiran and Suresh, 2014). As the gum karaya swells in water, thus in different formulations it is used as release rate controlling polymer. It possessed higher erosion and very low hydration capacity. Under investigation, zero order drug release is observed along with erosion of matrices (Kuppast and Vasanthkumar Pai, 2014).

\section{Okra Gum}

Okra gum collected from the pods of Hibiscus esculentus, Yields high viscosity mucilage at low concentrations. Okra gum, one of the advantageous polysaccharides and hydrophilic polymer currently being studied in the pharmaceutical industry as a pharmaceutical dosage forms. Okra gum contains different coil polysaccharides consisting of rhamnose, galactose and galacturonic acid are 
used as a tablet binding agent and to produce tablets with good friability, hardness and drug release profiles. Due to its chemically inert, safe, biodegradable, nonirritant, ecofriendly and biocompatible properties it has advantage over most commercial synthetic polymers because it is widely harvested and don't require toxicology studies. Okra gum is beneficial as a retarding polymer in the formulation of sustained release tablets as extraction in water give highly viscous solution with slimy appearance (Zaharuddin et al., 2014).

\section{Locust Bean Gum}

Locust bean gum known as Carob bean gum is derived from the seeds of the leguminous plant Ceratonia siliqua Linn, consists basically of neutral galactomannan polymer made up of 1, 4-linked D-mannopyranosyl units with every fourth or fifth chain unit is substituted on C6 with a D-galactopyranosyl unit. There is variation in ratio of Dgalactose to D-manose based on varying origins of the gum source materials and growth effecting conditions of the plant during production (Beneke et al., 2009). LBG is more effective to use as a gelling, stabilizer and thickening agent (Kivrak et al., 2015) and shows a wide variety of application in preparation and development of various novel drug delivery systems (Dey et al., 2012).

\section{Psyllium Husk}

Psyllium comes from the plant Plantagopsyllium, the husk and seed of Plantagoovata is referred to as psyllium. Psyllium is classified as a mucilaginous fiber due to its powerful gel forming ability in water (Patil et al., 2014). Psyllium husk is biocompatible, inert, swellable, biocompatible, inexpensive and easily available and environment friendly polymeric substance. The seed contains sterols, unsaturated fatty acids ranging $5-10 \%$ lipids, traces of cyclopentano pyridine-type alkaloids, proteins (15-18\%), aucubi, trisaccharide, carbohydrates-planteose, and 10-12\% mucilage of the heteroxylan type. Psyllium husk serve as reliable means for gastro retentive drug delivery system as it shows release retardant properties Researchers have also focused on prolonged retention of dosage form use in the GIT; stomach (Ishida and Kumar, 2013).

\section{Tamarind Gum}

Tamarind xyloglucan also called as Tamarind Kernel Powder (TKP) is collected from seed of the tamarind tree, Tamarindus indica, a member of the evergreen family. Tamarind gum; a polysaccharide composed of galactosyl: xylosyl: glucosyl in the ratio of 1:2:3. Higher plant primary cell walls has major structural polysaccharide called Xyloglucan and used as binder, gelling agent, stabilizer and thickener in pharmaceutical and food industries (Mali et al., 2012). Tamarind gum used in formulating matrix tablets are evaluated for its drug release characteristics by wet granulation technique. Different concentrations of polymers are used in tablets preparation. Decrease in drug release is observed with increase in polymer content (Choudhary and Pawar, 2014).

\section{Tara Gum}

Tara gum is obtained from family Leguminosae or Fabaceae from the endosperm of seed of Caesalpinia spinosa. Tara gum is odorless and white powder. Like, guar and locust bean gums, major component is galactomannan polymers consist of a linear main chain of (1-4)- $\beta$-D-mannopyranose units with $\alpha$-D-galactopyranose units attached by (1-6) linkages. The ratio of galactose to mannose is $1: 3$, produce highly viscous thick solutions, at $1 \%$ concentration
(Krishna et al., 2011). Tara gum is used in formulation of gastro retentive controlled release tablets and emulsions for drugs in pharmaceutical industries like nifedipine, metformin hydrochloride, carvedilol, clozapine and ciprofloxacin hydrochloride nimodipine has been claimed in patents. Good gastro retentive property is observed using tara gum in combination increases floating time of the dosage form. Tara gum also used in formulation of emulsions (MH and Mathew, 2015).

\section{IN-VIVO EVALUATION}

\section{Radiology}

For internal body systems examinations X-rays are widely used. One most widely used Radio Opaque Marker is Barium Sulphate so widely used in Dosage forms and GR imaging is done by X-rays at intervals (Pandey et al., 2012). Now a days $X$-Ray is used in floating dosage forms for assessment parameters. One can conclude and correlate the route of dosage form and gastric empting time in the GIT.As the result for the solid dosage form radio opaque material visual is done by X-Rays (Neetika and Manish, 2012)

\section{Gamma Scintigraphy}

$\gamma$-camera or scinti scanner is used for the indirect observation of a formulation by the involvement of a $\gamma$ emitting radio nucleotide. In $\gamma$-scintigraphy, the $\gamma$-rays emitted by the nucleotide are directed on a camera, which aids to focus and view to locate the location of the dosage form in the gastrointestinal tract (Chhetri and Thapa, 2014; Kumar et al., 2011).

\section{Gastroscopy}

Peroral endoscopy is also known as gastroscopy used with video systems or fiber optics and used to observe visually the evaluation of GRDDS and effect of prolongation in stomach (Kumar et al., 2012b).

\section{Magnetic Marker Monitoring}

In this method, iron powder is magnetically used as marker inside the dosage form and images are resulted by highly sensitive bio-magnetic measuring equipment. It is more beneficial as it has no radiations making it safer. Structures are elegantly checked by the help of iron powder and pictures are taken in accurate and delicate bio-attractive way (Waghmare Sneha et al., 2015).

\section{Ultrasonography}

They are used occasionally as it does not show results in intestine. Imaging of some abdominal organs is obtained in the interface on the reflection of substantially different acoustic impedances. As fine acoustic results on interference with physiological milieu are not achieved by the DFs therefore it is not used on regular bases for conclusion of FDDS. The characterization included solvent penetration in the gel, interactions among gastric wall and FDDS during peristalsis and assessment of intra gastric location of the hydrogels (Neetika and Manish, 2012; Khan, 2013).

\section{C Octanoic Acid Breath Test}

In GRDDS due to stomach chemical reactions octanic acid releases $\mathrm{CO}_{2}$ gas through the breath so $13 \mathrm{C}$ Octanoic Acid is incorporated in it. Major thing observed in this reaction is the formation of $13 \mathrm{C}$ isotope instead of the $\mathrm{CO}_{2}$ gas. Dosage form gastric retention time is observed with the passage of time in release of $13 \mathrm{CO}_{2}$ gas. This method is cheaper and as the dosage form reaches the intestine there no $\mathrm{CO}_{2}$ gas is observed (Chauhan et al., 2013). 


\section{DISCUSSION}

The objective of this review is to provide the overview of role of natural polymers in floating drug delivery system, its characteristic effects, ongoing research and trend of future developments and applications in the field. The physical characteristics of natural polymers facilitate them to be brilliant drug carriers for such type of drug delivery systems.

\section{REFERENCES}

Bangalore, S., Kumar, S., Fusaro, M., Amoroso, N., Attubato, M.J., Feit, F., Bhatt, D.L., Slater, J., (2012). Short and long-term outcomes with drug eluting and bare metal coronary stents: A mixed treatment comparison analysis of 117762 patient-years of follow-up from randomized trials. Circulation, CIRCULATIONAHA. 112.097014.

Beneke, C.E., Viljoen, A.M., Hamman, J.H., (2009). Polymeric plant-derived excipients in drug delivery. Molecules, 14(7), 2602-2620.

Bhowmik, D., Chiranjib, B., Chandira, M., Jayakar, B., Sampath Kumar, K., (2009). Floating drug delivery system-a review. Der Pharmacia Lettre, 1(2), 199-218.

Campo, V.L., Kawano, D.F., Da Silva, D.B., Carvalho, I., (2009). Carrageenans: Biological properties, chemical modifications and structural analysis-a review. Carbohydrate Polymers, 77(2), 167-180.

Chatrchyan, S., Khachatryan, V., Sirunyan, A.M., Tumasyan, A., Adam, W., Bergauer, T., Dragicevic, M., Erö, J., Fabjan, C., Friedl, M., (2014) Measurement of higgs boson production and properties in the wW decay channel with leptonic final states. Journal of High Energy Physics, 2014(1), 96.

Chauhan, P., Patel, M., Patel, N., (2013). Review on gastroretentive drug delivery systems. Indian Journal of Drugs and Diseases, 2(10), 218-230.

Chhetri, H.P., Thapa, P., (2014). An overview on gastroretentive drug delivery system. infection, 5, 12.

Choudhary, P.D., Pawar, H.A., (2014). Recently investigated natural gums and mucilages as pharmaceutical excipients: An overview. Journal of pharmaceutics, 2014

Dey, P., Maiti, S., Sa, B., (2012). Locust bean gum and its application in pharmacy and biotechnology: An overview. International Journal of Current Pharmaceutical Research, 4(1), 7-11.

Gomber, C., Parihar, S., (2013). Envisioning the role of renewable energy sources for a sustainable future. International Journal of Environmental Engineering and Management, 4, 25.

Goswami, S., Naik, S., (2014). Natural gums and its pharmaceutical application. Journal of Scientific and Innovative Research, 3(1), 112-121.

Goyal, M., Prajapati, R., Purohit, K.K., Mehta, S., (2011). Floating drug delivery system. Journal of current pharmaceutical research, 5(1), 7-18.

Ishida, H., Kumar, G., (2013). Molecular characterization of composite interfaces Springer Science \& Business Media.

Kajale, A.D., Chandewar, A.V., (2013). Recent advancement in gastroretentive drug delivery system-a review. Indo Am J Pharm Res, 3, 5221-5232.

Kanavaje, A.M., Kanekar, A.S., Patil, A.B., Fugate, A.R., Battase, A.P., (2014). Iontophoretic drug delivery: A novel approach through transdermal route. Int. J. Pharm. Review \& Res, 4(3), 160-165.

Khan, R., (2013). Gastroretentive drug delivery system-a review. Int J Pharm Bio Sci, 4(2), 630-646.

Kıvrak, N.E., Aşkın, B., Küçüköner, E., (2015). Comparison of some physicochemical properties of locust bean seeds gum extracted by acid and water pre-treatments. Food and Nutrition Sciences, 6(02), 278.

Kola, R., Kumar, B.P., (2013). A detailed description of synthetic and natural polymers which are used in the formulation of sustained release drug delivery system: A review. Journal of Chemical and Pharmaceutical Sciences, 6(3), 161-169.

Krishna, L.N.V., Kulkarni, P., Dixit, M., Lavanya, D., Raavi, P.K., (2011) Brief introduction of natural gums, mucilages and their applications in novel drug delivery systems-a review. IJDFR, 2, 54-71.

Kulkarni, V.S., Butte, K.D., Rathod, S.S., (2012). Natural polymers-a comprehensive review. Int J Res Pharm Biomed Sci, 3(4), 1597-1613.
Kumar, D., Saini, S., Seth, N., Khullar, R., Sharma, R., (2011). Approaches, techniques and evaluation of gastroretentive drug delivery system: An overview. International journal of research in ayurveda and pharmacy, 2(3), 767-774.

Kumar, S., Gupta, S.K., Sharma, P.K., (2012a). A review on recent trends in oral drug delivery-fast dissolving formulation technology. Advances in Biological Research, 6(1), 06-13.

Kumar, S., Jamil, F., Rajput, M., Sharma, S., (2012b). Gastro retentive drug delivery system: Features and facts. International Journal of Research in Pharmaceutical and Biomedical Sciences, 3(1), 125-130.

Kuppast, I., Vasanthkumar Pai, K., (2014). Phytochemical investigation and evaluation of antimicrobial and antitubercular activity of kunstleria keralensis.

Makwana, A., Sameja, K., Parekh, H., Pandya, Y., (2012). Advancements in controlled release gastroretentive drug delivery system: A review. Journal of Drug Delivery and Therapeutics, 2(3).

Mali, Y., Pawar, S., Gujarathi, N., Rane, B., Bakliwal, S., (2012). Pharma science monitor.

Mh, A., Mathew, F., (2015). Recent advances in topical gel formulation.

Mishra, A., Gupta, P., (2012). 4. Gastro retentive drug delivery system: A review. International Journal of Drug Development and Research.

Nayak, K.P., (2012). Gastroretentive drug delivery systems and recent approaches: A. Journal of pharmaceutical research and opinion, 2(1), 1-8.

Neetika, B., Manish, G., (2012). Floating drug delivery system. IJPRAS, 1(4), 20-28.

Pandey, A., Kumar, G., Kothiyal, P., Barshiliya, Y., (2012). A review on current approaches in gastro retentive drug delivery system. Asian Journal of Pharmacy and Medical Science. Vol, 2, 4.

Patil, D.R., Zhou, Y., Kang, J.-E., Sharpes, N., Jeong, D.-Y., Kim, Y.-D., Kim, K.H., Priya, S., Ryu, J., (2014). Anisotropic self-biased dual-phase low frequency magneto-mechano-electric energy harvesters with giant power densities. APL Materials, 2(4), 046102.

Raj, A.a.S., (2012). A review on pectin: Chemistry due to general properties of pectin and its pharmaceutical uses (2012). Open access scientific reports, 1, 12.

Reddy, B.V., Navaneetha, K., Deepthi, P.S.A., (2013). Gastroretentive drug delivery system-a review. Journal of Global Trends in Pharmaceutical Sciences, 4(1), 1018-1033.

Sahoo, R., Sahoo, S., Nayak, P.L., (2013). Synthesis and characterization of gelatin-chitosan nanocomposite to explore the possible use as drug delivery vehicle. European Scientific Journal, 9(18).

Sai Rekha, G., Battu, S., Rao, U.M., (2015). A review on various polymers and approaches used to design pulsatile drug delivery system.

Sarathchandiran, I., Suresh, K., (2014). Characterization and standardization of gum karaya. International Journal of Biopharmaceutics, 5(2), 142-151.

Shah, A.A., Kamdar, K., Shah, R., Keraliya, R.A., (2013). Emulgel: A topical preparation for hydrophobic drugs. PharmTechMedica, 2, 370-376.

Singh, A., Sarkar, D.J., Singh, A.K., Parsad, R., Kumar, A., Parmar, B.S., (2011). Studies on novel nanosuperabsorbent composites: Swelling behavior in different environments and effect on water absorption and retention properties of sandy loam soil and soil-less medium. Journal of applied polymer science, 120(3), 1448-1458.

Tekade, B.W., Chaudhari, Y., (2013). Gums and mucilages: Excipients for modified drug delivery system. J. Adv. Pharm. Edu. E Res, 3(4).

Thirawong, N., Nunthanid, J., Puttipipatkhachorn, S., Sriamornsak, P., (2007). Mucoadhesive properties of various pectins on gastrointestinal mucosa: An in vitro evaluation using texture analyzer. European journal of Pharmaceutics and Biopharmaceutics, 67(1), 132-140.

Waghmare Sneha, S., Kadam Trupti, V., Darekar, A., Saudagar, R., (2015). A review: Floatable gastroretentive drug delivery system. Asian J. Pharm. Res, 5(1), 51-60.

Zaharuddin, N.D., Noordin, M.I., Kadivar, A., (2014). The use of hibiscus esculentus (okra) gum in sustaining the release of propranolol hydrochloride in a solid oral dosage form. BioMed research international, 2014. 